\title{
001 A PRODUCTION WELL FOAM PILOT IN THE NORTH SEA SNORRE FIELD - APPLICATION OF FOAIN TO CONTROL PREMATURE GAS BREAKTHROUGH
}

IDAR SVORSTØL, TORE BLAKER, MIN JACK THAM and ANDERS HJELLEN Saga Petroleum ASA, PO Box 490, 130,1 Sandvika, Norway

\begin{abstract}
This paper discusses the design, field operation, data acquisition and the performance of a foam pilot conducted in the North Sea Snorre field in mid-1996. The foam pilot was carried out in P-18, a high volume producer with peak production rate at $6000 \mathrm{Sm}^{3} /$ day, which had been shut-in since it experienced premature gas breakthrough from WAG injection. The primary objectives of the pilot were to transfer laboratory tested foam technology to field application, to reduce the high GOR of P-18, and to return the well to production status. A comprehensive data aquisition programme was conducted for the interpretation of results. The pilot operation was carried out smoothly without major operational problems. The pilot demonstrated that it is possible to generate a strong foam in an oil bearing formation and to selectively block gas flow in a high permeability zone. P-18 was returned to production as a consequence of GOR being reduced by about $50 \%$ for more than 2 months. The foam pilot further demonstrated that foam treatment is a viable improved oil recovery process for the Snorre reservoirs.
\end{abstract}

\section{INTRODUCTION}

Snorre is one of the major oil fields on the Norwegian Continental Shelf in the North Sea, located about 150 kilometres off the coast. The current estimate of ultimate recovery (proved and probable) is in excess of 200 million $\mathrm{Sm}^{3}$ of oil. The reservoir is a massive fluvial deposit, contained within rotated fault blocks. The field was originally developed with water injection as the main drive mechanism and it was put on stream in 1992.

At the time of production start up in 1992, a reserves enhancement potential was already identified and a plan to mature these reserves were implemented. This included the testing of reservoir continuity and the qualification of EOR and advanced well technologies through pilot testing. Based on promising results from early studies of WAG injection, a pilot was implemented in $1994^{1,2}$ which consisted of a 5-well pattern in the central part of the field. Early gas breakthrough was realised in P-18, which had to be shutin due to export gas limitations. However, the remaining producers did not experience gas breakthrough like P-18. With positive response in the remaining pilot area and favourable economics, it was decided in 1995 to expand the WAG injection to cover the three main fault blocks in the field.

With this decision the injected gas volume will increase from about 1 million $\mathrm{Sm}^{3} / \mathrm{day}$ to 5 million $\mathrm{Sm}^{3} /$ day in 1998 . This highlights a large challenge to control gas breakthrough in the producers and to improve the sweep efficiency of the injected gas. The main candidate to meet this challenge is foam and the work on the Snorre foam qualification programme was intensified. The qualification of foam technology started in parallel with the Norwegian Government sponsored research programme RUTH ${ }^{3}$ and an active collaboration with RUTH on experimental and modelling work was carried out.

Since P-18 was shut-in due to early gas breakthrough in 1994, it became a prime candidate for foam treatment. P-18 has intermittently tested high GOR since shut-in. The test was carried out in mid-1996 for the purpose of transferring laboratory tested foam technology to field applicatication, to reduce the 
high GOR of P-18 and to return the well to production status.

The pilot was designed based on integrated results from laboratory and simulation studies. ${ }^{47}$ The surfactant used in the test, a commercial grade $C_{14 / 16}$ alpha olefin sulphonate (AOS), was selected based on criteria set for solubility, adsorption, foam properties, health and environmental safety: considerations, availability, and cost. ${ }^{46}$ This paper discusses the foam pilot design and operation, data aquisition, and the pilot performance.

\section{PILOT DESIGN AND OPERATION}

A schematic diagram of the cross-section of producer P-18 is given in Figure 1. Previous PLT logs indicated that approximately $90 \%$ of the free gas produced from P-18 came from S10, the uppermost sand layer of the Statfjord Formation. The RST log also identified high gas saturation in the upper part of the $\mathrm{S} 10$ sand. This sand has a gross thickness of $7.2 \mathrm{~m}$, and is isolated from the zones below by a shale layer that is believed to extend a significant distance into the formation. The average permeability of $\mathbf{S 1 0}$ is approximately 8 Darcy. The intention with the foam treatment was to selectively inject a slug of a high viscosity blocking foam into the $\mathrm{S} 10$ zone in order to block the flowing of gas into the well.

The foam pilot operational procedure and the data acquisition programme are illustrated in Figure 2 . The operation was conducted according to this plan with only minor deviations.

The comprehensive data acquisition programme consisting of production tests before and after foam treatment, PLT \& RST logging, downhole pressure monitoring, transient pressure testing, and tracer tracking technology were integrated into the pilot design to provide a framework for interpretation of the foam performance, and to better understand the flood front conditions and fluid interactions in the reservoir. Additional platform surface facilities and oil field chemicals were introduced to control anticipated problems of gas hydrate formation, asphaltene depositions, process emulsions and discharged water foaming. The fluid injection system was modified to accommodate injection of multiple fluids simultaneously.

Well P-18 was put on production for about one week in order to establish a pre-pilot production baseline. A combined PLT/RST log was run before foam injection to obtain the production profile before foam treatment. An isolation bridge plug was then set at the shale layer below the $\mathrm{S} 10$ sand, followed by a short production test (Figure 1).

During the pre-flush water injection, $2030 \mathrm{Sm}^{3}$ of pre-heated sea water was injected into the well at 1000 $\mathrm{Sm}^{3} /$ day to displace the high oil saturation at the vicinity of the well. The sea water which has a temperature of $5-10^{\circ} \mathrm{C}$ was heated to $60^{\circ} \mathrm{C}$ with a small steam generator to prevent gas hydrate formation in the tubing. This was done to avoid using methanol which is a foam killer. Following the sea water, $100,000 \mathrm{Sm}^{3}$ of gas was injected at $300,000 \mathrm{Sm}^{3} /$ day to prevent the sea water from diluting the surfactant solution and to further reduce the oil saturation. Following the sea water injection as well as the gas injection, a 12-hour shut-in period was allowed for pressure fall-off test.

A total of 32 tons of commercial grade $\mathrm{C}_{14 / 16} \mathrm{AOS}$ was used, 8 tons for each surfactant-altemate-gas (SAG) cycle and 16 tons for the co-injection. The first SAG injection was planned to consist of $150 \mathrm{Sm}^{3}$ of $2 \mathrm{wt} \%$ surfactant solution followed by $106,000 \mathrm{Sm}^{3}$ gas. Due to control problems with the surfactant pump, a total of $295 \mathrm{Sm}^{3}$ solution with $1 \mathrm{wt} \%$ surfactant was injected, followed by $109,000 \mathrm{Sm}^{3}$ of gas. The second SAG cycle went according to plan. There was a 10-hour pressure fall-off test following each SAG injection cycle. 
The SAG cycles were followed by co-injection of $300 \mathrm{Sm}^{3}$ of $2 \mathrm{wt} \%$ surfactant solution and $212,000 \mathrm{Sm}^{3}$ gas, giving a foam quality of $70 \%$. During the co-injection period there was a 7-hour interruption in injection when the entire Snorre field was shut-down.

The well was then shut-in for 10 hours for pressure fall-off test, after which the isolation bridge plug was retrieved and 2 electronic memory pressure gauges were installed at the end of the production tubing. The combined PLT/RST log was run and the well returned to production.

The operation was carried out smoothly without major technical problems. The smooth operation of the foam pilot can be attributed to the precaution taken to prevent the anticipated gas hydrate formation in the production tubing, any uncontrollable emulsion generation in the test separator, asphaltene build-up in the tubing and casing, and excessive foaming in the discharge water. ${ }^{8}$

During the SAG and the co-injection each surfactant slug was labelled with a different water tracer and each gas slug was labelled with a different gas tracer. Samples for tracer analysis were taken up to two months after the injection.

Bottomhole injection pressure were lost twice: (1) during the start of the pre-flush gas injection when the PLT tool was used to monitor the temperature at the sub-surface safety valve for possible hydrate formation, and (2) during the gas injection in the second SAG, when the PLT tool was pulled up to the lubricator due to a small gas leak at the well-head HPMV valve. Except for this, the data acquisition programme worked according to plan, and gave good information from the entire operation.

\section{PILOT PERFORMANCE AND DISCUSSION}

The bottomhole pressure development during the injection operation (Figure 3) clearly indicates that the foam generation during the two SAG cycles was limited, and that it was mainly the co-injection that resulted in the generation of a strong foam.

During the pre-flush water injection, the bottomhole injection pressure increase was approximately 10 bar, while it increased by 5 bar during the pre-flush gas injection. At the end of the first SAG injection the bottomhole pressure increased by about 8 bar. During the second SAG, no pressure data was available due to the small gas leakage and the pulling of the PLT tool. There was no pressure fall-off data for the second SAG cycle.

The co-injection of surfactant and gas started after the well head gas leak was fixed. P-18 bottomhole pressure increase was about 55 bar after 8 hours of co-injection. At that point P-18 had to be shut-in because the entire Snorre production was shut-down. The co-injection of surfactant and gas into P-18 was resumed 7 hours later. At the end of the co-injection period, P-18 bottomhole pressure was 380 bar which was close to the pressure limit set for the test to avoid fracturing the formation.

The large pressure increase of 80 bar shown in Figure 3 clearly demonstrates that it was possible to generate a strong foam in an oil bearing formation by co-injection of surfactant and gas. The pressure increase that was observed after the Snorre shut-down could be due to ageing effects in the foam. In the laboratory experiments the $C_{14 / 16}$ AOS foam was found to become stronger with ageing. ${ }^{4,5}$

The pressure increase during the two SAG cycles was only 8-10 bar. It is probable that most of the surfactant in the first slug was adsorbed. For the second SAG pressure data are missing for the gas injection, but gas rate measurements did not indicate that any significant foam was created. Previous PLT logs had indicated the possibility of a secondary gas cap present at the $\mathrm{S} 10$ sand. The presence of a gas cap can cause segregated flow for SAG injection, which can result in poor mixing of the surfactant and 
gas, poorer quality foam and smaller volume of foam being generated, particularly at the top of the formation.

Figure 4 shows the test separator results before and after foam treatment in P-18. During the 6 days of production test before foam treatment P-18 GOR increased to $470 \mathrm{Sm}^{3} / \mathrm{Sm}^{3}$. The GOR appeared to be inversely dependent on oil production rate. After foam placement the isolation bridge plug was retrieved. P-18 was produced at 3 rates $\left(500,1200\right.$ and $2400 \mathrm{Sm}^{3} /$ day) during the post foam PLT logging. When the well was flowed at the high oil rate of $2400 \mathrm{Sm}^{3} / \mathrm{day}$, the GOR was $320 \mathrm{Sm}^{3} / \mathrm{Sm}^{3}$ and water rate was 500 $\mathrm{Sm}^{3} /$ day. P-18 did not produce any water before foam treatment. Shortly after the PLT logging, P-18 was shut-in because no test separator was available. When production was resumed 2 weeks later the water rate dropped to an insignificant level. The GOR was about half of the pre-treatment level, it became more stable and appeared to be independent of production rate. This apparent change in production behaviour after the shut-in may also be due to ageing effects in the foam. ${ }^{46}$ As seen from Figure 4 the foam appears to remain effective for about 2 months and slowly losing its effectiveness with the GOR gradually increasing to the level before foam treatment.

The continuous bottomhole pressure data recorded with the PLT tool during the fluid injection period and with the memory gauges during the production period were used to conduct pressure fall-off and pressure build-up analyses. From these analyses an apparent foam viscosity of $60 \mathrm{cp}$ was estimated, which is equivalent to a mobility reduction factor (MRF) of 260 when compared with gas mobility during the pre-flush gas injection.

The interpretation of the production logs before and after foam treatment (Figure 5) indicated that there was crossflow from S12 and S51 into the S31 sand before foam treatment. After the foam treatment cross-flow was absent and the S31 sand started to contribute to P-18 production. Before foam treatment, $\mathrm{P}-18$ produced at high GOR and low drawdown pressure (ca. $5 \mathrm{bar}$ at $1200 \mathrm{Sm}^{3} /$ day). Cross-flow in S31 took place because S31 formation pressure was lower than the bottomhole pressure. After foam treatment the flow of free gas in the $\mathrm{S} 10$ sand was blocked by foam and it required a larger drawdown pressure (ca. $13 \mathrm{bar}$ at $1200 \mathrm{Sm}^{3} /$ day) to produce the well. S31 started to produce oil because the S31 formation pressure now was higher than the bottomhole pressure.

The tracer concentration and surfactant concentration in the liquid and gas samples ${ }^{9}$ collected during foam injection and during back production were used to evaluate the foam performance. Based on the measured injected water tracer concentration, produced water tracer concentration and produced water rate, the back production rate of each surfactant solution slug was computed by material balance calculation. The back production rate of the slugs of surfactant solution from the two SAG injections and the co-injection are shown in Figure 6. The water rate that can not be accounted for by the tracer material balance calculation is considered to be that of the pre-flush water. These water rates are represented by the open circles in the figure. According to the sequence of injection, the surfactant solution front of the first SAG cycle was to be the furthest away from the well bore because it was injected first. The surfactant solution in the co-injection phase was injected last and should therefore be closest to the well bore. In Figure 6 the co-injection surfactant solution was produced back at the highest rate in the first sample. After the first sample the co-injection surfactant solution rate dropped rapidly below those of the two SAG cycles and remained low for the rest of the production period. This indicates that the foam generated during co-injection was much stronger and flowed back much slower than those generated during the two SAG injection cycles.

The back production rates of the gas slugs injected during the two SAG cycles and the co-injection period are computed based on the material balance calculation of gas tracers in the injected and produced gas phase. In Figure 7 the gas slüg injected during the first SAG cycle, which was expected to be the 
furthest away from the well bore, was seen to produce back at the highest rate. The gas slug injected last during co-injection was seen to back produce at the lowest rate.

These results support the observation from the injection pressure data that foam generated by the two SAG cycles was much weaker than that generated by the co-injection, probably caused by adsorption and segregation. As a result the gas which did not form foam would segregate and flow back faster than the gas being trapped in the foam.

A field demonstration of foam for mobility control is the next step in Saga's development of foam technology, the Foam Assisted WAG ${ }^{10}$ project (FAWAG). Large volumes of surfactant will be used in an injector treatment where the well spacing is more than $1000 \mathrm{~m}$. The P-18 pilot has given valuable operational experience and data to tune foam reservoir simulators. The FAWAG project will take place in 1997/98, and is financially supported by the European Commission's Thermie Programme.

\section{CONCLUSIONS}

The following conclusions can be made:

- A strong foam was generated in an oil bearing formation during co-injection

- After foam placement a mobility reduction factor (MRF) of 260 was estimated based on pressure falloff analysis

- GOR was reduced by about $50 \%$ for more than 2 months

- The $\$ 31$ formation layer was changed from a negative contributor to a positive contributor of P-18 oil production due to increased drawdown

- The pilot provided valuable experience in the application of tracer technology to evaluate foam stability and foam integrity in-situ

- The operation (setting of packer, injection of chemicals, back production) was carried out without major technical problems

- The treatment increased the Snorre operational cash flow by putting P-18 back on production for more than 2 months

- The P-18 pilot provided valuable experience for the planning of the upcoming injector foam treatment pilot (FAWAG).

\section{ACKNOWLEDGEMENTS}

The authors gratefully acknowledge Saga Petroleum ASA and the Snorre Field license partners for permission to publish this paper. They also want to thank the Saga Petroleum ASA staff members who have participated in the development and field implementation of the foam technology.

\section{REFERENCES}

1. Nybråten, G., Svorstøl, I. and Andfossen, P.O.: "WAG Pilot Evaluations for the Snorre Field," 7th European IOR Symposium, Moscow, Russia, October 27-29, 1993.

2. Stenmark, H. and Andfossen, P.O.: "Snorre WAG Pilot - A Case Study," 8th European IOR Symposium, Vienna, Austria, May 15-17, 1995.

3. RUTH 1992-1995, A Norwegian Research Programme on Improved Oil Recovery, NPD, Stavanger 1996.

4. Mannhardt, K. and Svorstøl, I.: "Foam Propagation in Snorre Reservoir Core: Effects of Oil Saturation and Ageing," 9th European IOR Symposium, The Hague, Netherlands, October 20-22, 1997.

5. Svorstøl, I., Vassenden, F., and Mannhardt, K.: "Laboratory Studies for Design of a Foam Pilot in the Snorre Field," SPE/DOE 35400, 10th Symposium on Improved Oil Recovery, Tulsa OK, 21-24 April, 1996. 
6. Svorstøl, I., Blaker, T., Holt, T., and Vassenden, F.: "Foam Pilot Evaluations for the Snorre Field. Part 1: Project Planning and Laboratory Results," 8th European IOR Symposium, Vienna, Austria, May 15-17, 1995.

7. Svorstøl, I., Arneson, S., and Surguchev, L.M.: "Foam Pilot Evaluation for the Snorre Field. Part 2: Numerical Simulations and Economical Evaluations," 8th European IOR Symposium, Vienna, Austria, May 15-17, 1995.

8. Blaker, T., Svorstøl, I. and Tham, M. J. , "Use of Chemicals in the Snorre Foam Pilot", 8th International Oil Field Chemical Symposium, Norway, 2-5 March 1997.

9. Eriksen, D.Ø., and Brendsdal, E., "Monitoring Foam Behaviour by Tracer Technology”, RESERVE, Norwegian Reserve Research Programme on IOR, IFE, 1996.

10.Hanssen, J.E., Surguchev, L.M., Svorstøl, I. and Blaker, T.: "SAGA Injection: A New Combination IOR Process for Stratified Reservoirs," 7th European IOR Symposium, Moscow, Russia, October 2729, 1993.

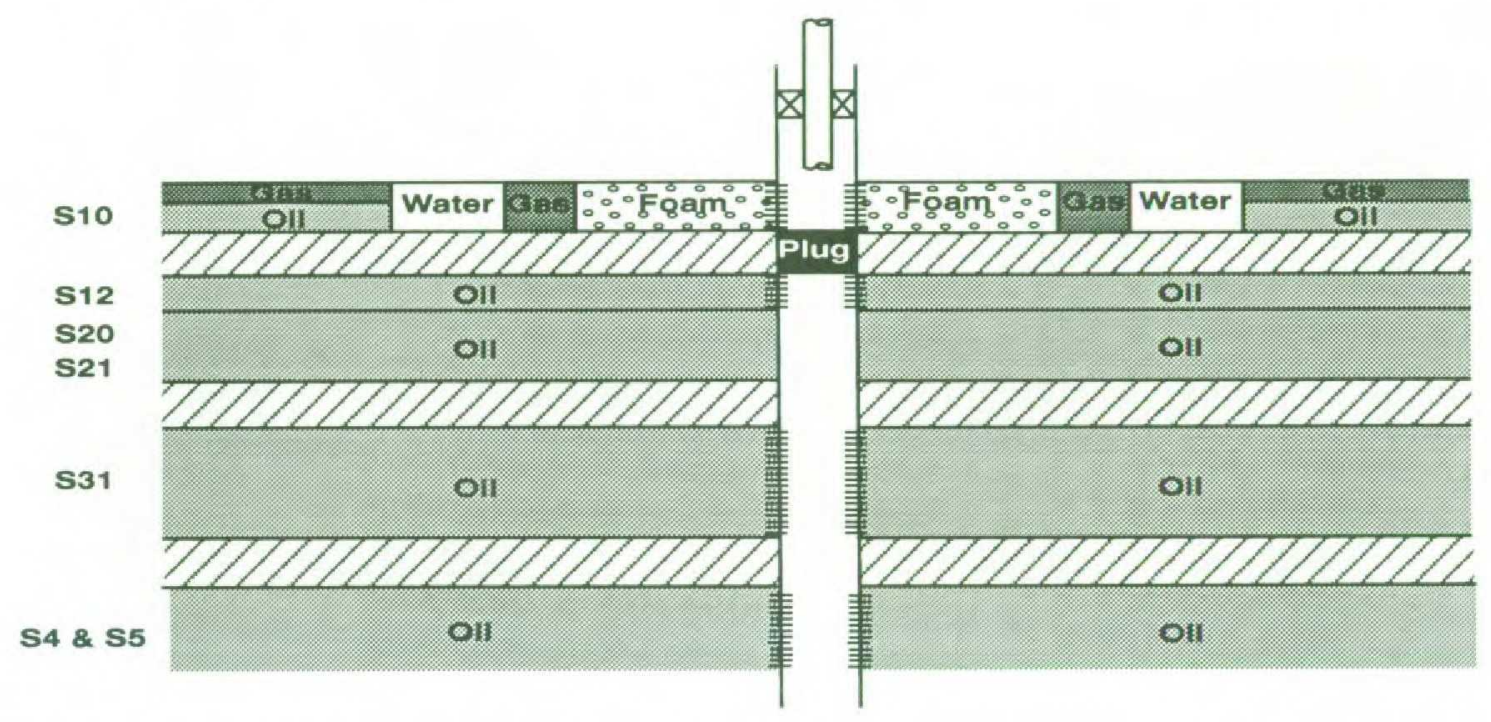

Figure 1. Cross-section of the P-18 well, schematic.

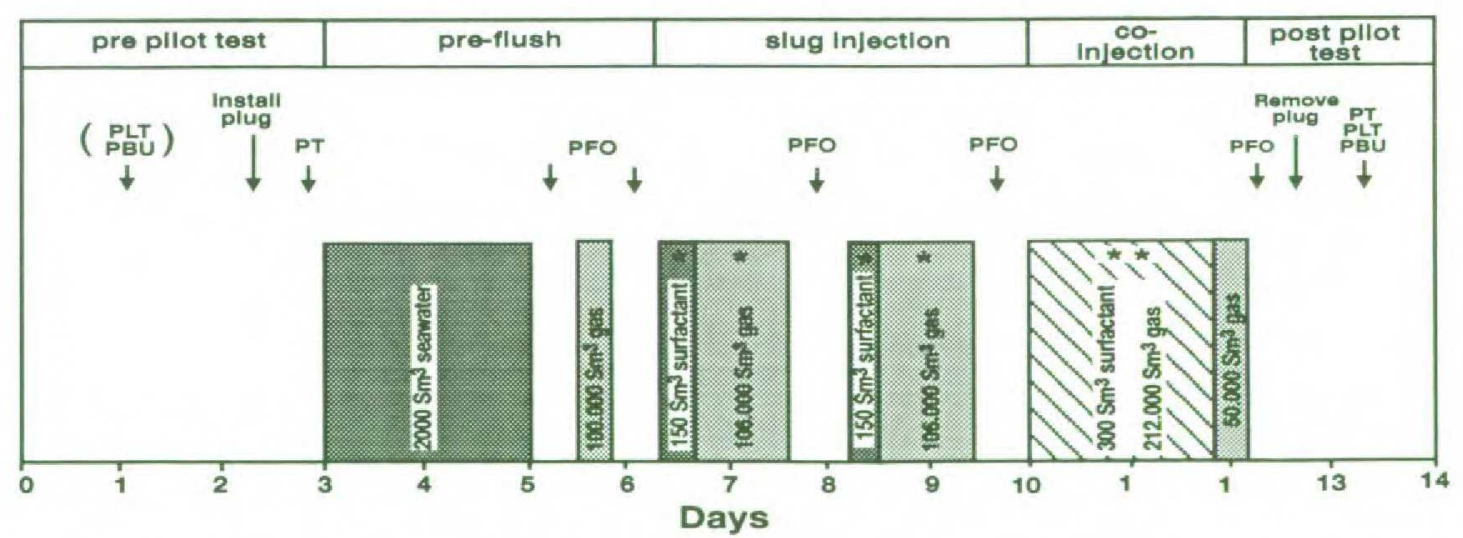

\begin{tabular}{|llll|}
\hline & & PLT & Production log \\
PT & Tracer Injection & PFO & Pressure fall off test \\
\hline & Production test & PBU & Pressure bulld up test \\
\hline
\end{tabular}

Figure 2. P-18 foam pilot design. 


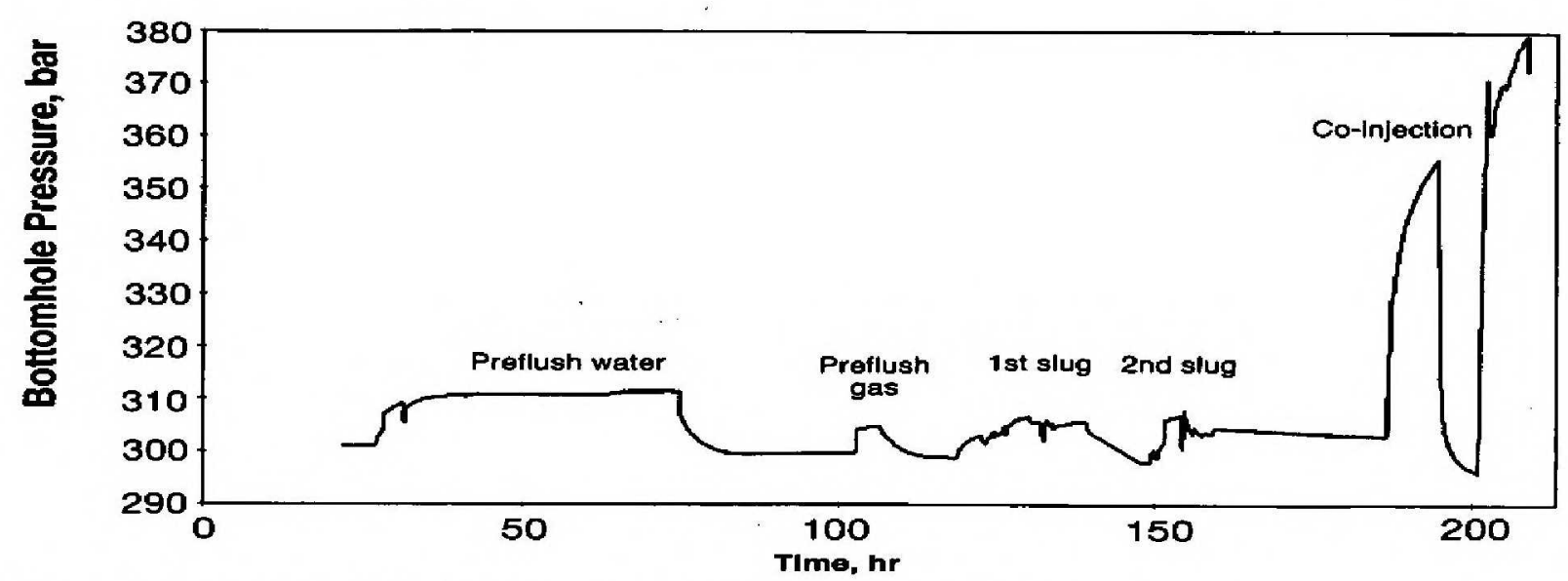

Figure 3. Bottomhole injection pressure during the injection scenario.

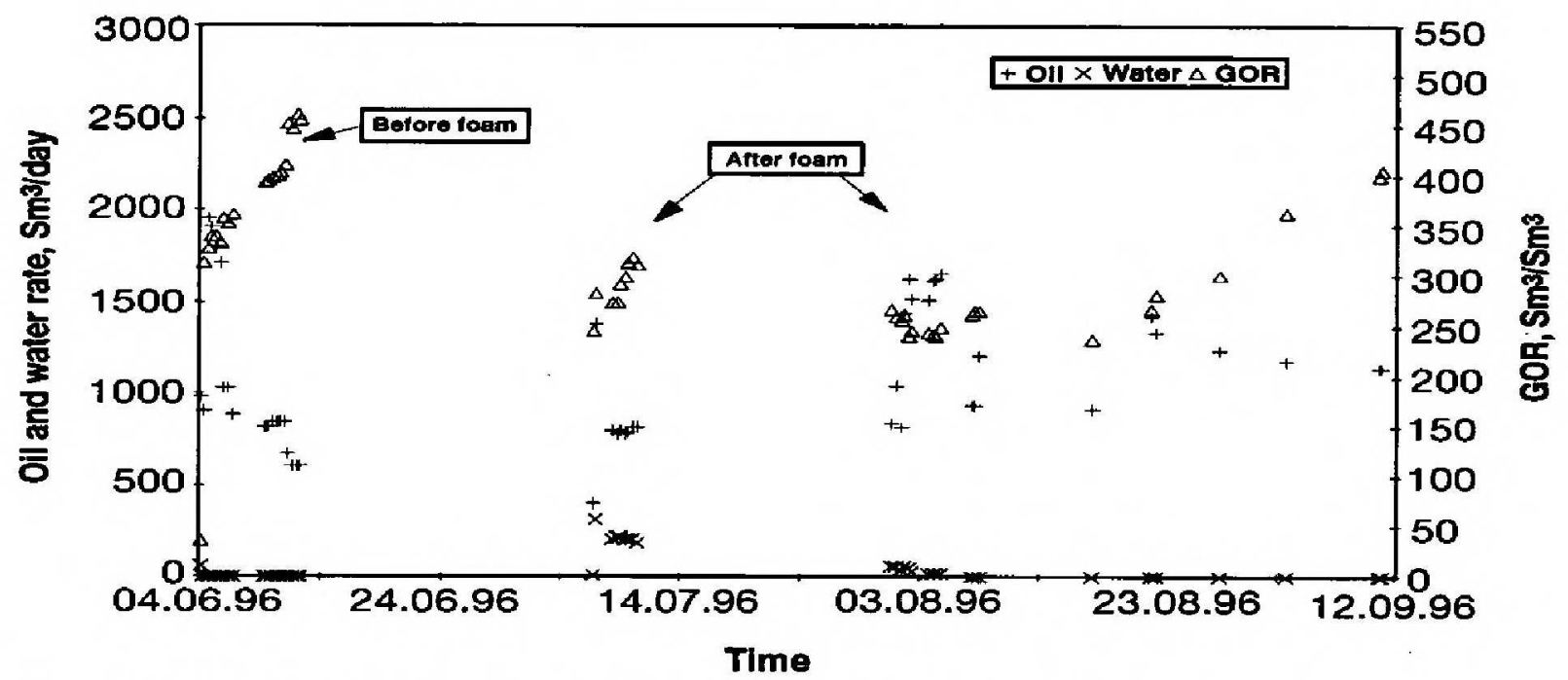

Figure 4. GOR, oil rate and water rate before and after foam treatment.

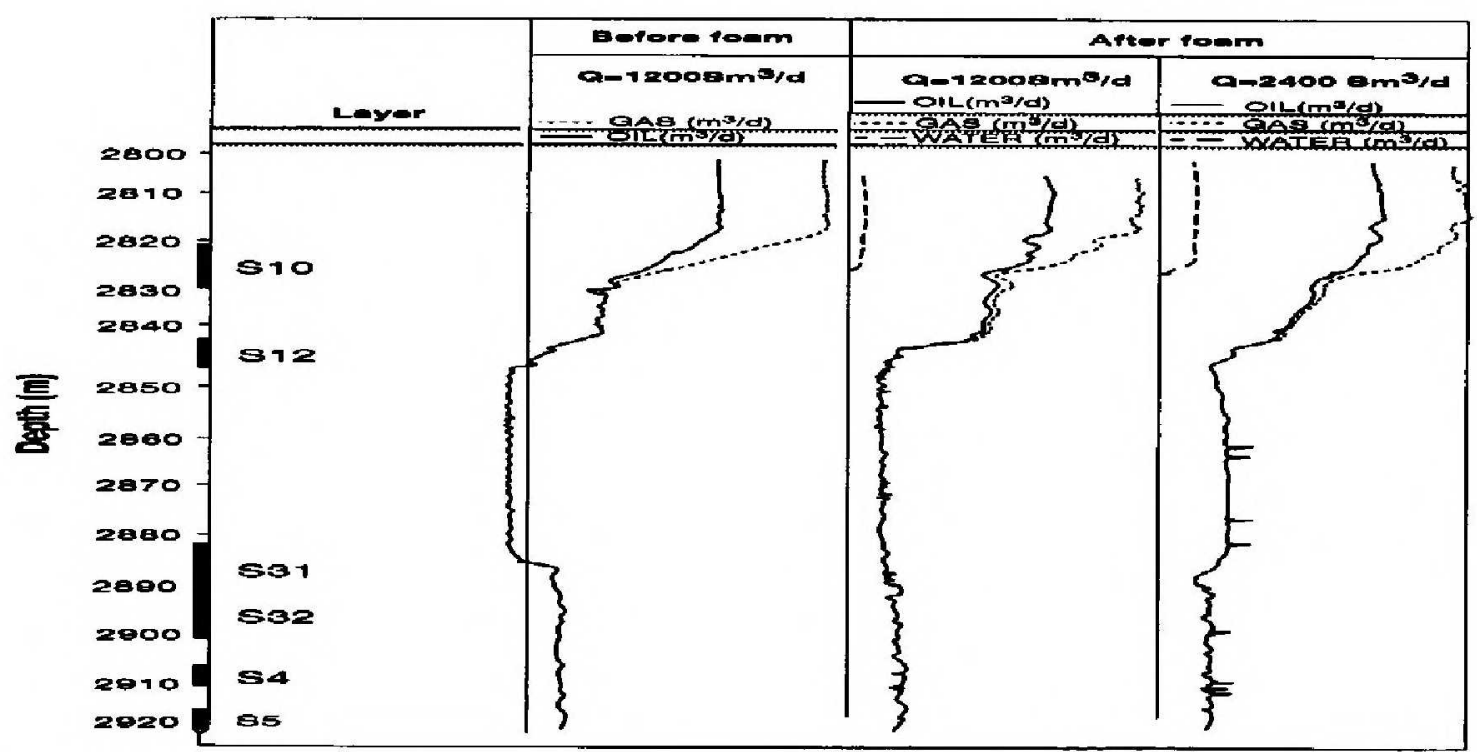

Figure 5. PLT logging before and after the foam treatment. 


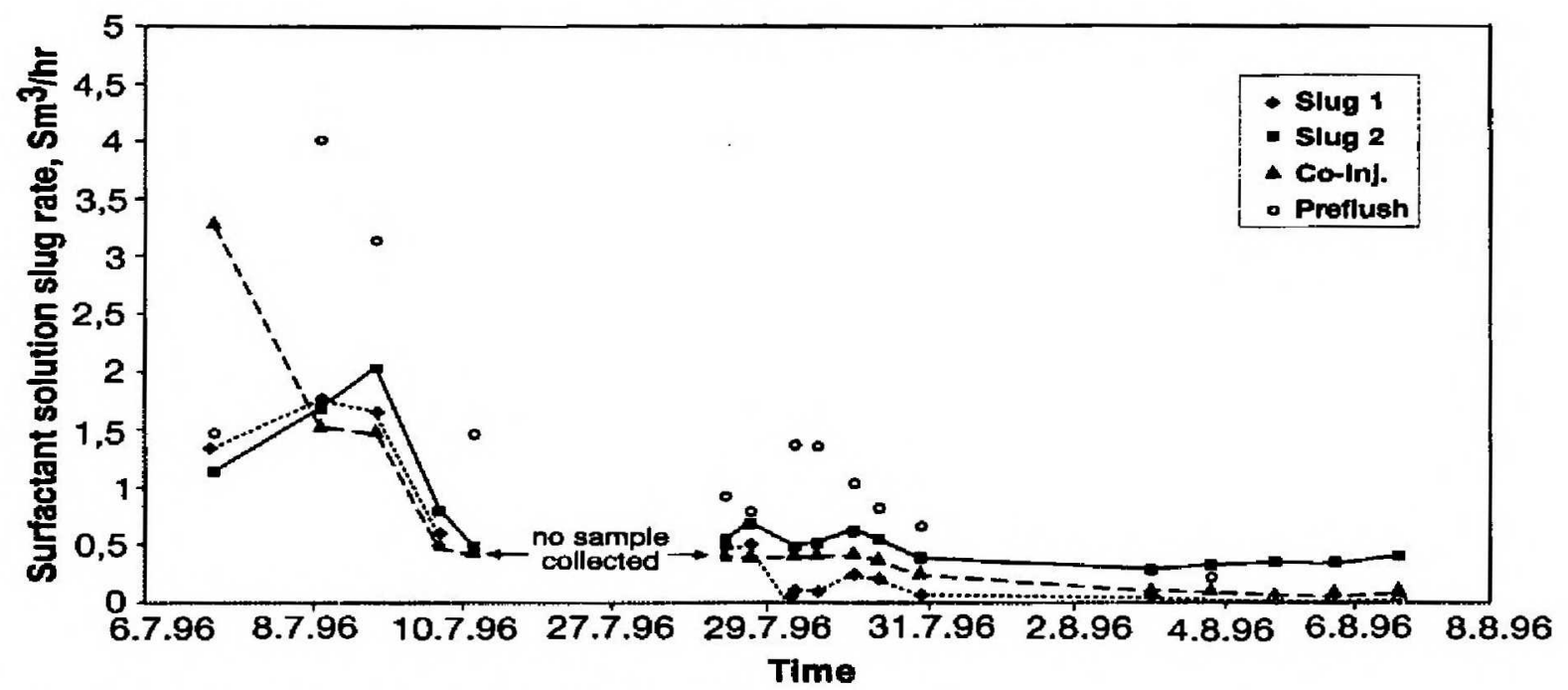

Figure 6 Produced surfactant slugs labelled with water tracers.

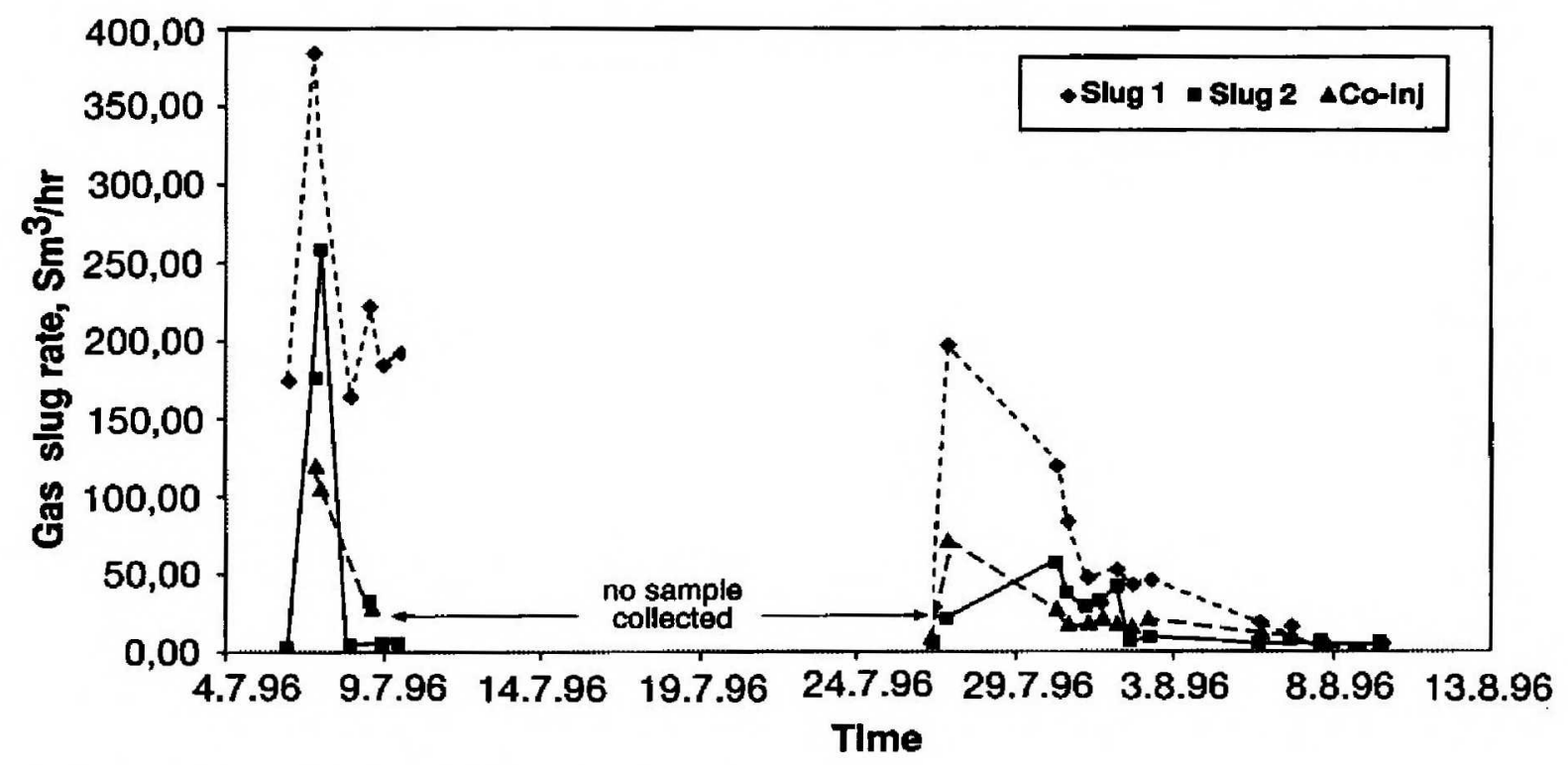

Figure 7. Produced gas slugs labelled with gas tracers. 